\title{
Stress equation for a cantilever beam: a model of lodging resistance in field pea
}

\author{
Jamin A. Smitchger ${ }^{1 *}$, Norman Weeden ${ }^{2}$, Idil Akin ${ }^{3}$, and Tom Warkentin ${ }^{4}$ \\ ${ }^{1}$ Department of Crop and Soil Sciences, Washington State University, PO Box 646420, Pullman, WA, USA 99164-6420 \\ ${ }^{2}$ Department of Plant Sciences \& Plant Pathology, Montana State University, PO Box 173150 Bozeman, MT, USA 59717-3150 \\ ${ }^{3}$ Civil and Environmental Engineering, Washington State University, PO Box 642910, Pullman, WA 99164 \\ ${ }^{4}$ Plant Sciences, Crop Development Centre, University of Saskatchewan, 2C04-Agriculture Building, Saskatoon, SK, Canada S7N 5A8
}

Received December 17, 2019; accepted February 13, 2020

\begin{abstract}
Mechanically harvested crops must be erect (lodging resistant) to facilitate harvest. Stem lodging changes canopy structure, increases disease pressure, reduces yield, and reduces harvest efficiency in pea. A number of studies have examined the traits that cause lodging susceptibility, but the relative impact of each trait is difficult to determine. A great need exists in pea breeding to develop a working model to explain lodging resistance. This study used the flexure formula to predict the amount of lodging variation explained by some of the major traits. Datasets from pea indicate that the percent variation explained by this lodging model is $\sim 58 \%$, and this model can be used to predict the relative impact of an increase in load, height, stem diameter, stem wall thickness, or yield on lodging susceptibility. This study indicates that plant height is strongly correlated with lodging susceptibility, but stem diameter is positively correlated with lodging resistance. Stem wall thickness appears to have no major effect on lodging resistance, which has not been previously reported in pea. Any doubling in plant height would also double the amount of stem material, but stem stress is expected to increase fourfold. A doubling in stem diameter is expected to increase the amount of stem material by fourfold and decrease stem stress by eightfold. The results of this study indicate that plant breeders should focus on increasing basal stem diameter to increase lodging resistance.

Ke y w rod s: Pisum sativum, pea, lodging, stem strength, lodging susceptibility, flexure formula
\end{abstract}

\section{INTRODUCTION}

Mechanically harvested crops must be erect (lodging resistant) to facilitate harvest, and in the past lodging resistance has ranked only behind yield in importance in pea breeding programs (Stelling, 1989). Peas are lodg-

\footnotetext{
*Corresponding author e-mail: jsmitchger@wsu.edu
}

ing susceptible due to their growth habit, which partially depends on tendrils for support (Swinhoe et al., 2001). In pea, when plants lodge, a humid microclimate is often created that promotes fungal diseases (Kaatz and Gritton 1975; Swinhoe et al., 2001; Banniza et al.,, 2005; Tar'an et al., 2003; Jha et al., 2013) and premature germination (Swinhoe et al., 2001). Lodging also increases yield losses during harvest (Kaatz and Gritton, 1975; Schouls and Langelan 1994; Banniza et al., 2005; Wang et al., 2006; Jha et al., 2016). Yield loss occurs by two mechanisms: when pods fall below the cutter level at harvest, and when normal canopy structure is destroyed, resulting in reduced photosynthetic ability, lower dry matter production, and increased damage from pathogens and pests (Kaatz and Gritton, 1975; Chen et al., 2011). Yield losses due to lodging in pea have not been thoroughly reported, but in soybean lodging has been shown to cause yield losses of $11-32 \%$ (Chen et al., 2011). It is reasonable to expect that yield losses in pea would be more severe than in soybean since pea is not normally an erect crop. Lodging also slows harvest because machine operators need to be more careful with header placement, resulting in more operator hours during mechanical harvesting.

It was dwarfing genes in wheat and rice that allowed the development of varieties that powered the Green Revolution (Hedden, 2003). In pea breeding a breakthrough in lodging resistance came in the 1980's with the development of dwarf (le) varieties with the semi-leafless (afila)

(C) 2020 Institute of Agrophysics, Polish Academy of Sciences 
trait (Goldenberg, 1965). Le, also known as Mendel's tall/ dwarf gene (Mendel, 1866), influences plant height and stem diameter (Smitchger and Weeden, 2019), with the recessive le allele causing the dwarfing phenotype. The afila gene converts leaflets to tendrils in the compound leaf, increasing the number and length of tendrils per plant and allowing the plants to intertwine for mutual support, thereby creating a truss system of interlocking members (Stelling, 1989; Tar'an et al., 2003; Kof et al., 2004; Mikel, 2013; Klimek-Kopra et al., 2015). All commonly grown dry pea cultivars in Europe and North America are le and afila, but some varieties with the le and afila alleles heavily lodge. Therefore, leaf morphology and short stature are insufficient to achieve an upright growth habit (McPhee and Muehlbauer, 1999).

Existing cultivars have lodging resistance to varying degrees, but lodging susceptibility is associated with many factors, whose contributions are not well understood. In a recent review on lodging in grains, lodging was correlated with plant height, panicle and peduncle length, cell wall thickness, stem diameter, stem wall thickness, area of xylem, the number of vascular bundles, and lignin, starch, silicon, hemicellulose, and cellulose content. Agronomic factors such as sowing date, seeding rates, crop rotation, soil rolling, type of tillage system, type of irrigation system, nitrogen fertilization rate, timing of nitrogen fertilization, and phosphorus and potassium fertilization also play a role (Shah et al., 2017). It is well known that increasing plant density decreases stem diameter per plant, increases internode length, and decreases lodging resistance (Xue et al., 2016). However, Spies et al. (2010) indicated that relatively high seeding rates are needed to optimize crop yield. Kosev and Mikic (2012) indicated that lodging resistance in pea is positively correlated with branch number, number of pods per plant, number of seeds per plant, number of fertile nodes per plant, number of seeds per pod, seed yield per plant, and branch length. Banniza et al. (2005) found significant positive correlations between the proportion of xylem and supportive tissue and lodging resistance, even though no significant differences among cultivars were observed. Acid detergent fiber, acid detergent lignin, and cellulose were also analyzed and the amount of each was found to be positively correlated with lodging resistance. However, only limited variation in lignin content was found in cultivars, a result which was confirmed by Beeck et al. (2006). Other research in peas indicates that lodging resistance is positively correlated with branch number, number of pods per plant, number of seeds per plant, number of fertile nodes per plant, number of seeds per pod, seed weight per plant, and branch length, and negatively correlated to 1000 seed weight (Kosev and Mikic, 2012). In soybean plant height, internode length, stem diameter, node number, branch number, stem (breaking) strength, root systems, lignin and cellulose content, silicon content, environmental conditions, fertilization, and disease can influence lodging (Chen et al., 2017). In peas (Elkoca et al., 2006) and wheat (Shah et al., 2017) plant growth regulators can decrease lodging susceptibility. Several studies have shown that quantitative trait loci (QTLs) which influence lodging susceptibility in peas also control plant height (Tar'an et al., 2003; Inoue et al., 2004). Climatic and biotic factors that might influence lodging include wind, precipitation, hail, humidity, disease pressure, and insect infestation. Wind may increase the load borne by plant stems. Precipitation could soften stem material and facilitate biotic degradation of stem walls, leading to settling of the crop after a hard rainfall. Hail can cause lodging by mechanical damage. Humidity may affect the stiffness of the stem, and disease pressure might weaken the stem material due to damage. Insect infestation due to stem boring insects such as wheat stem sawfly has also been shown to influence lodging in small grains (Fulbright et al., 2017).

Several studies have focused on improving stem strength to decrease lodging in pea (Beeck et al., 2006; and Beeck et al., 2008a, b). Pea is essentially a climbing vine, and in many landraces, the dead load caused by the weight of the upper part of the plant is enough load to make the plant fall over, even in controlled conditions. Erectness has been achieved in commercial cultivars, but environmental conditions such as wind often cause lodging in cultivated lines. Since the basal part of the stem is the area where bending occurs, increasing stem strength in the basal region of the stem is likely to increase resistance to lodging. Beeck et al. (2006) focused on stem diameter and wall thickness and used a metric of load to determine the traits associated with strength of the pea stem. The best predictor of load as measured in the study was compressed stem thickness $\left(\mathrm{R}^{2}=0.92\right)$ followed by stem diameter $\left(\mathrm{R}^{2}=0.80\right)$. There was a positive response to selection for compressed stem thickness, which had an average broad sense heritability of 0.64 (Beeck et al., 2008a, b). Skubisz et al. (2007) also concluded that stem wall thickness was correlated with the strength and lodging potential of pea stems. Banniza et al. (2005) indicated internode diameter at node 2-3 explained $16 \%$ of the variation in lodging.

While many factors have been shown to influence lodging resistance in peas and other crops, the relative importance of each factor is not always well understood. In engineering, the flexure formula (Stubbs et al., 2018) has been adapted to determine the stress on a tubular cantilever beam. This adapted equation is commonly used in engineering to design flagpoles, wind turbine towers, bridge supports, buildings, and other structures. This study used an in-silico modeling approach with the flexure formula in combination with empirical data to identify the load on the stem, the length of the stem, its diameter, and the thickness of the stem wall as four critical parameters that determine the probability of structural failure. A similar approach was first used by Schwendener (1874) who studied the mechanical properties of plant stems. Both Schwendener (1874) 
and Rasdorsky (1929) argued that plant stems with their interwoven strands of parenchyma, sclerenchyma, and collenchyma fibers were complex composite materials similar in a modern sense to steel reinforced concrete (Niklas et al., 2006). Schulgasser and Witztum (1992) further concluded that the flexibility of plant stems could reconfigure stem and wind loading since plants bent close to the ground would have less area exposed the wind and that the flexibility of leaves and clusters of leaves in wind can allow them to be oriented at an angle that reduces drag on the stem. Schulgasser and Witztum (1992) also examined the relationship between the orientation of rigid structural layers in the stem and stem stress, concluding that the position of the rigid structural elements in the plant stem was directly related to flexibility and compressive failure of stems. Banniza et al. (2005) published highly detailed photographs of the pea stem detailing the position of structural fibers but did not examine those photographs from a plant biomechanical perspective. A review of the extensive field of plant biomechanics has been published (Niklas et al., 2006), but the plant biomechanical literature is primarily beyond the scope of this article. This study will look at plant biomechanics of pea stems from a plant breeding perspective to understand the traits and characteristics influencing lodging resistance in pea.

\section{MATERIALS AND METHODS}

The major recombinant inbred line (RIL) population used in this study was developed from a cross between two pea varieties, a cultivar named Delta, and RER, a pea line with more primitive traits. Delta is semi-leafless (afila), has short internodes (le), and is a commercially produced variety. Dr. Norman Weeden at Montana State University developed RER from several crosses. RER was chosen for its erect growth despite having wild type leaves (Afila) and long internodes $(L e)$. There were $254 \mathrm{~F}_{2}$ lines derived from the Delta $x$ RER cross. A secondary RIL mapping population called the PR population was sourced from Dr. Tom Warkentin at the University of Saskatchewan and planted in 2015 in both Bozeman and Moccasin, MT. This population was entirely semi-dwarf (le/le) and semi-leafless (af/af) being derived from a cross between the commercial lines Carerra and CDC Striker (Gali et al., 2018). It was composed of 144 lines including the two parents.

Each $\mathrm{F}_{2}$ plant from the Delta $\mathrm{x}$ RER cross was eventually advanced via single seed descent to the $\mathrm{F}_{7}$ generation. The $\mathrm{F}_{5}$ RIL population was planted at the Montana State University Post Agronomy Farm with one replication in 2014 , and the generation was again advanced in a greenhouse at Montana State University. In 2015, the $\mathrm{F}_{7}$ population was planted with three replications using a randomized complete block design at both the Post Agronomy Farm in Bozeman, MT, USA and the Central Agricultural Experiment Station in Moccasin, MT, USA. The seeding rate at the Bozeman location in 2014 and 2015 was $\sim 40$ seeds $\mathrm{m}^{-2}$ due to lack of seed. The seeding rate was 25 seeds $\mathrm{m}^{-2}$ in Moccasin in 2015. Data was averaged across replications. The secondary PR population from the University of Saskatchewan was planted in the same manner as the Delta $x$ RER population, except only one replication was planted in both locations, and the population was only planted one year. In 2016, the $\mathrm{F}_{7}$ families from the Delta x RER population were planted in the same locations with just a single replication in both Bozeman and Moccasin. There were seven check plots for each of the parents within each replication during both 2015 and 2016. Because it was believed that data would be more similar to commercial field conditions when planted at higher densities, in 2016 the planting density was increased to $\sim 60$ seeds $\mathrm{m}^{-2}$ in Bozeman and $\sim 43$ seed $\mathrm{m}^{-2}$ in Moccasin, MT. Cultivation regimes were conventional tillage in Bozeman and no-till in Moccasin. Row spacing was $19 \mathrm{~cm}$ in Bozeman, MT and $30.5 \mathrm{~cm}$ in Moccasin, MT during all site-years. Seeds were planted in microplots with three rows per plot. During 2014 and 2015, due to lack of seed, three seeds were planted in the border rows, and four seeds were planted in the middle row for a total of ten seeds per plot. During 2016, eight seeds were planted in the two border rows and 9 seeds were planted in the middle row. Due to the difficulty associated with treating each RIL, no seed treatment was used, but seeds were inoculated with N-dure for Peas, Vetch, and Lentil (Verdesian Life Sciences, Cary, North Carolina) during 2014 and 2016.

Data were collected for canopy height, total stem length, main stem diameter, compressed main stem thickness, side branch diameter, compressed side branch thickness, and epicotyl diameter. Leaf type (Af), and Mendel's height gene $(L e)$, which were segregating in the population, were also assessed.

Canopy height was measured on 1-4 individual plants per plot as the distance from soil level to the last node of the main stem. The stem length of these plants was measured from ground level to the last node of each plant. Percent lodging was determined by using the following formula: \% lodging for each RIL = (1-(canopy height/stem length) $\times 100$. This method was reported by Stelling et al. (1989) to be an accurate method of lodging assessment. Percent lodging was rated at senescence for individual RILs.

Each plant stem was collected by clipping off the upper part of the plant above the fifth node. The root and stem epicotyl were then removed from the ground using a shovel. The main stem and side branches of pea appear to be very similar at first glance, but there are a number of characteristics that distinguish main stems from side branches. In general, the main stem is continuous from the root to its tip, and it generally has shorter internodes than side branches. Side branches have a visible scar where they attach to the stem (Fig. 1). Side branches are easily stripped from the 


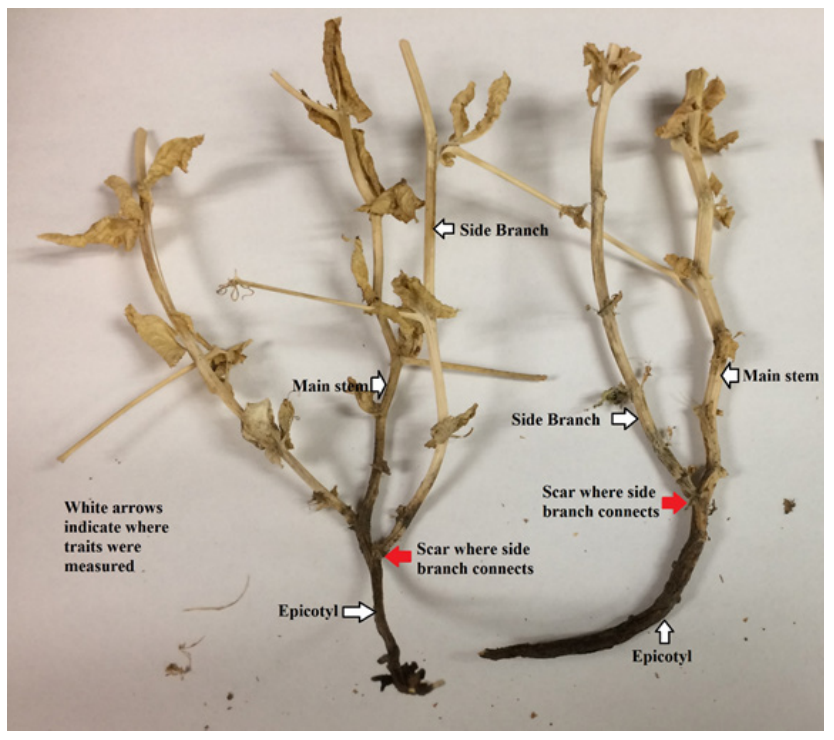

Fig. 1. White arrows indicate where stem characteristics traits were measured. Stems were usually measured between the third and fourth nodes on the main stem and side branches (white arrows).

main stem with a gentle tug, leaving a scar on just one side of the main stem. Both the main stem and side branch were measured between the third and fourth node on the main stem and the side branch. The largest diameter side branch was always rated. Side branches that connected to the main stem close to the ground were always preferred over side branches farther from the ground.

Stem and side branch diameter, compressed stem and side branch thickness, and epicotyl diameter were measured using a generic $0-150 \mathrm{~mm}$ electronic digital caliper with an accuracy of $0.01 \mathrm{~mm}$. Each stem was measured at the place where bending due to lodging thought to occur. In general, stems were measured between the third and fourth nodes. If the stem was buried deeply in the ground (indicated by a brownish discoloration at the third or fourth nodes), the stem was measured between the fourth and fifth nodes or very rarely at the fifth and sixth node. This procedure was used because the below ground stem in pea is not hollow and compressed stem thickness could not be assessed if the stem is solid. Main stem diameter and compressed main stem thickness were assessed at the same location on the stem. Side branch diameter and compressed side branch thickness were also assessed at the same location. Compressed stem thickness and compressed side branch thickness were assessed by firmly compressing the stem between the calipers until it could not be compressed further. The thickness was then recorded. Epicotyl diameter was assessed in the middle of the epicotyl. In 2014, all plants that emerged ( 2000 plants) were assessed for main stem diameter, compressed main stem thickness, side branch diameter, and compressed side branch thickness ( $~ 8000$ measurements). In 2015, 2500 plants were assessed for each of the two locations, and epicotyl diam- eter was included in the analysis ( 20000 measurements). The PR population, the additional RIL population which was sourced from the University of Saskatchewan, was rated for stem diameter, side branch diameter, and epicotyl diameter on $\sim 900$ plants in 2015. In 2016, stem diameter, side branch diameter, and epicotyl diameter were assessed on $\sim 2000$ plants in the Delta $\mathrm{x}$ RER population. Means for the two parents and the RIL population were averaged over site years. For the two parents, each of the repeated checks was averaged for each year and the mean value for each year was averaged over site years.

To calculate the maximum normal stress in the pea stem due to applied loads, the pea stem was modeled as a cantilever beam with a hollow circular cross section. Applied load is a difficult parameter to measure since plant characteristics, topography, wind speed, interactions between plants, stem rigidity (influenced by moisture), and numerous other factors can determine how load is distributed. In peas, because each plant is commonly connected to one or more other plants to some degree, load is often distributed among a series of interacting members. The purpose of this study was merely to provide a basic model for lodging resistance in peas, which would be useful in plant breeding to develop more lodging resistant cultivars. Therefore, for modeling purposes, a uniformly-distributed load $(w)$ was used to calculate the maximum normal stress $\left(\sigma_{\max }\right)$ from the flexure formula: $\sigma_{\max }=M y / I$, where $M$ is the resultant internal bending moment about the neutral axis of the cross section, $y$ is the distance from the neutral axis, and $I$ is the moment of inertia of the cross-sectional area about the neutral axis (Stubbs et al., 2018).

The maximum resultant internal moment $(M)$ due to the uniformly distributed load was determined from the moment diagram as $M=\left(w L^{2}\right) / 2$, where $L$ is the length of the pea stem in meters. The load per unit length (i.e., $w$ ) was standardized to be the expected wind load experienced by a $1 \mathrm{~mm}$ projected width of pea stem $1 \mathrm{~m}$ high. Using the equation $w\left(\mathrm{~N} \mathrm{~m}^{-1}\right)=1 / 2 \rho v^{2} b$, where $\rho$ represents the density of air $\left(\sim 1.2 \mathrm{~kg} \mathrm{~m}^{-3}\right.$ under normal conditions $), v$ represents wind speed in meters per second, and $b$ represents projected width in meters, a $1 \mathrm{~mm}$ wide stem section $1 \mathrm{~m}$ high would encounter a load of 0.29976 newtons of force at a wind speed of $80.47 \mathrm{~km} \mathrm{~h}^{-1}$. This force is then multiplied by the height squared in meters. For a hollow circle, the neutral axis passes through the center and maximum normal stress occurs at $r$ distance from the center, where $r$ is the outer radius of the circle in meters. The moment of inertia for the hollow circle is:

$$
I=\pi / 4\left(r^{4}-(r-t)^{4}\right),
$$

where: $t$ is the wall thickness in meters. Therefore, using the flexure formula for $y=r$, the maximum normal stress can be derived as: 


$$
\sigma_{\max }=\left(2 w L^{2} \mathrm{r}\right) /\left(\pi \left(r^{4}-(r-t)^{4},\right.\right.
$$

where: units of stress $\left(\sigma_{\max }\right)(\mathrm{Pa})$. These units were converted to MPa for clarity. Empirically derived stem radius and wall thickness measurements were used to calculate the maximum normal stress at the base of each plant under this ideal scenario.

\section{RESULTS}

The empirical data showed a consistent trend across site years. Therefore, data from the Delta x RER population was averaged over site years for the analysis with the stress equation. When load, height, and compressed stem thickness were held constant in the equation, main stem diameter alone predicted less than $6.9 \%$ of the variation in lodging in this population. When height was included in the model, the stress equation explained $28.8 \%$ of the variation in lodging in the Delta x RER population. Without using the equation, height alone predicted $45.8 \%$ of the variation in lodging. Within semi-leafless (afila) and normal leafed (Afila) lines alone, respectively, the stress equation predicted 45.6 and $46.5 \%$ of the variation in lodging based on main stem radius, main stem wall thickness, and height. Within afila and Afila lines alone, respectively, plant height predicted 51.0 and $55.3 \%$ of the variation in lodging, respectively. To reduce experimental error, main stem radius, side branch radius, and epicotyl radius were averaged and main stem and side branch wall thickness were averaged. After averaging, the model explained 58.1 and $59.6 \%$ of the variation in lodging in $a f$ and $A f$ lines, respectively (Fig. 2).
A secondary analysis used the PR population, which was not segregating for Le or the Afila locus, to determine how well the stress equation predicted lodging. When main stem, side branch, and epicotyl diameter were averaged and other parameters were held constant, the stress equation predicted $30.0 \%$ of the variation in lodging in this population based on stem diameter alone. Height and lodging were strongly correlated $\left(\mathrm{R}^{2}=0.62\right)$. Stem diameter and height were strongly and negatively correlated $\left(\mathrm{R}^{2}=0.37\right)$. The stress equation predicted $58.0 \%$ of the variation in lodging in this secondary population with a linear model (Fig. 3) and $61.0 \%$ using a polynomial trendline. The polynomial trendline is not shown to increase simplicity.

\section{DISCUSSION}

Based on how well the empirically derived data fits the stress equation, the stress equation is a credible model for lodging resistance in peas. Varieties with the afila mutation have significantly lower stem diameter than wild type varieties (Singh and Srivastava, 2015), and in this study it is apparent that the two traits are genetically linked $\left(p=2.6 \times 10^{-7}\right)$. Therefore, the model is best at predicting lodging within leaf types in pea. In both of these populations stem diameter and height were negatively correlated. Therefore, stem diameter is a lurking variable that may explain why either height or stem diameter alone were good predictors of lodging, this effect was especially evident in the secondary PR population where height explained 37\% of the variation in stem diameter. This result indicates that taller plants have narrower stems. Therefore reducing plant height in these populations has a synergistic effect

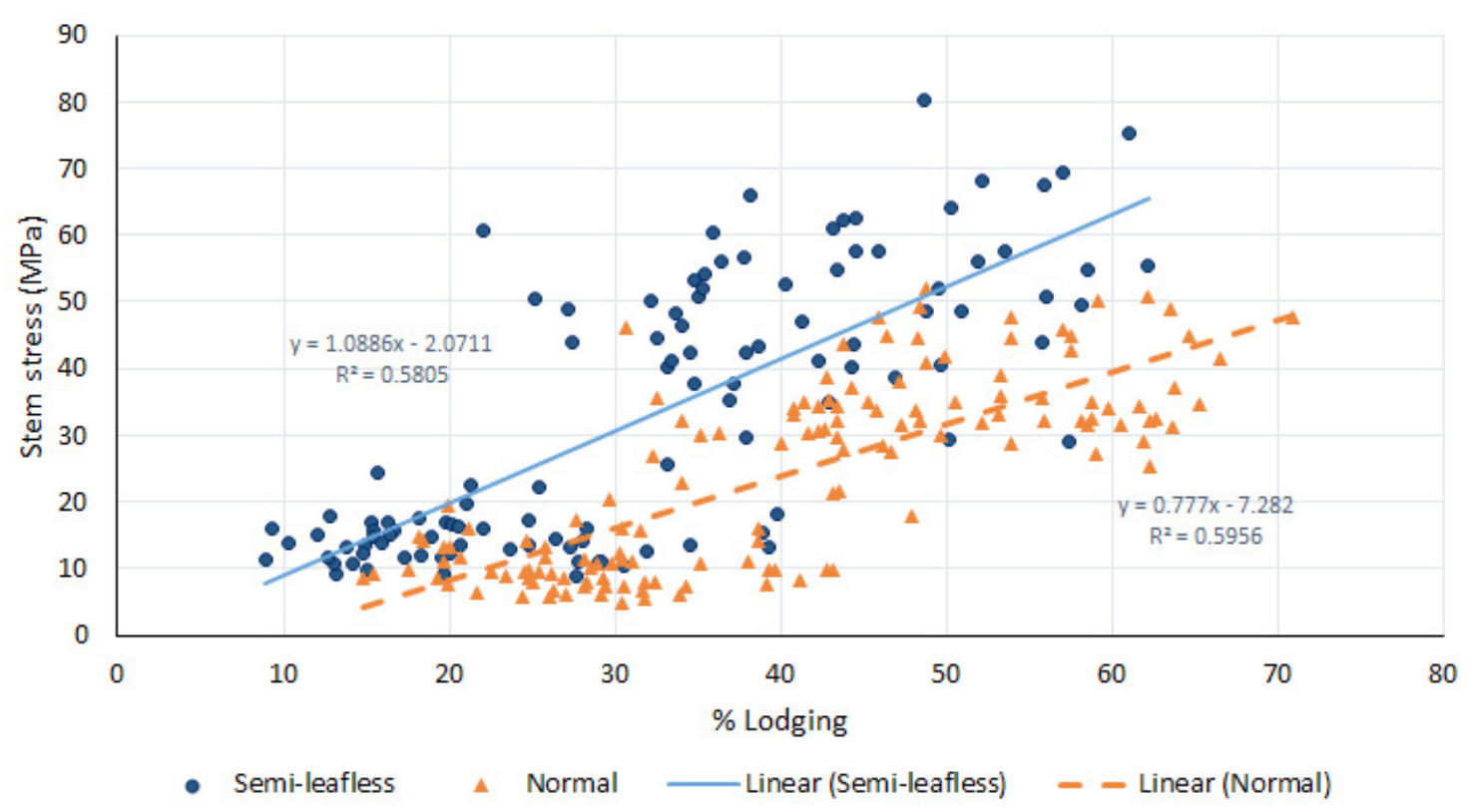

Fig. 2. Correlation between predicted stem stress and lodging in the Delta $x$ RER population. The blue line and dots represent the data for semi-leafless lines, and the orange line and dots represent the data for normal leafed lines. In this case normal leafed lines were predicted to have less stress than semi-leafless lines because semi-leafless lines have reduced stem diameter and compressed stem thickness. The model successfully predicts over $58 \%$ of the lodging within the two leaf types in the Delta x RER population. 


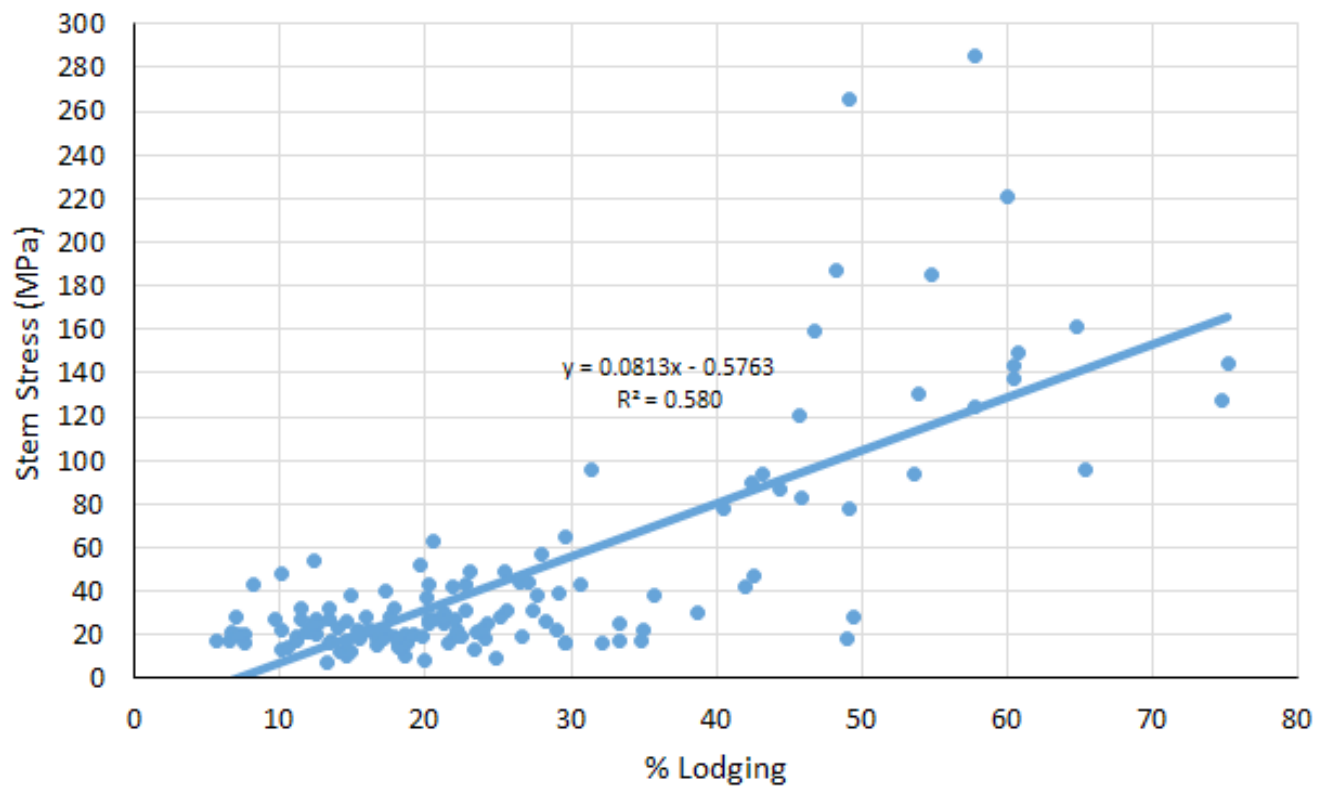

Fig. 3. The stress equation and lodging (PR population). The stress equation predicted $58 \%$ of the variation in lodging in this secondary population, which is consistent with the data from the Delta $x$ RER population, but the PR population had less lodging than the Delta $\mathrm{x}$ RER population.

of reducing stem stress. Nearly all height genes in pea are linked to gibberellin biosynthesis (Murfet and Reid, 1993), and Mendel's height gene (Mendel, 1866) was segregating in this population. Mendel's height gene had a strong effect on stem diameter $\left(\mathrm{p}=3.64 \times 10^{-24}\right)$ in the Delta $\mathrm{x}$ RER population. In peas, it was previously unknown that stem length and stem diameter are negatively correlated. It is possible that the increase in stem diameter with a decrease in height is also partly responsible for the superior lodging resistance of green revolution varieties of wheat, rice, or other crops. We therefore further examined this relationship in wheat using data stored in the Triticeae Toolbox (Blake et al., 2015) and derived from an association mapping study using 250 elite wheat varieties (Godoy et al., 2018), but in those elite lines stem diameter and height were weakly and positively correlated $\left(\mathrm{R}^{2}=0.0887, \mathrm{p}=0.037\right)$. Since tall lines with narrower stems would not become an elite cultivar, it is likely that these tall elite cultivars merely had thicker stems as a response to intensive selection for lodging resistance, and the question whether the synergistic relationship between height and stem diameter exists in green revolution varieties of other crops remains unresolved.

This study is based on approximately 30000 stem measurements and several thousand height measurements. While the model fits the empirical data fairly well, it should be noted that a large amount of subsampling variation exists for stem diameter and compressed stem thickness since these traits are strongly controlled by the environment. Therefore, the statistics for stem diameter may decrease the accuracy of the model due to random error. This is probably the reason why height was a better predictor of lodging than the stress equation in the secondary PR population, which had fewer stem measurements and hence more error in stem measurements than the Delta $x$ RER population. It should also be noted that the model did not explain $42 \%$ of the variation in lodging. Peas are unique due to their tendency to create a natural truss system of interlocking tendrils, which allows peas to remain upright despite their narrow stems. Any model of this truss system would likely be very complex, since a field of peas is essentially acting as a unit to resist load and environmental stresses.

The stress equation for a tubular cantilever beam identifies 4 specific factors that should influence lodging in a hollow-stemmed plant such as pea: load $(W)$, stem height $(L)$, stem diameter $(r)$, and stem wall thickness $(t)$. Mathematical calculations using the stress equation can be made to predict which component is most important from a plant breeding perspective.

Plant stems must be stiff enough to support both the load of their own weight and associated wind loads. In the field pea stems fail at the base of the plant because it is the location where stem stress is highest (maximum bending moment) for a beam supported by only one point. Pea stems rarely fail by buckling because they are rarely completely vertical. It should be noted that there is no cantilever loading due to plant weight when the stem is completely vertical and loads are equally distributed, but leverage due to the weight of the plant increases as pea stems assume angles closer to horizontal. Therefore, a partially lodged pea is much more likely to lodge than one that is completely erect. The equation indicates that load is expected to have a linear effect on stem stress with a doubling in load (yield/biomass/wind loading) increasing stress by two-fold. An attempt was made to estimate the load component of the stress equation by accounting for leaf length, grain yield, and theoretical stem weight. Accounting for 
leaf length increased the model fit to $60 \%$ in the Delta $x$ RER population, but it also greatly increased the complexity of the model. Node number, yield, and theoretical stem weight decreased fit, possibly due to inaccurate estimates of their effect. Therefore, the load component of the stress equation was not evaluated using an empirical dataset and was held constant for these analyses. It should be noted that exploratory data analysis using additional data that was not presented indicated that plant biomass itself is likely to be a poor metric of load since significant variation in plant habit and erectness can dramatically alter how load is distributed. There are multiple factors that could play a role in load and the distribution of load such as yield, erectness, pod weight, height to the lowest pod, harvest index, plant habit, node number, leaf number, leaf type, leaf weight, leaf length, stem diameter, peduncle length, branching, aerial branching, tendril number, tendril vigor, and tendril spacing. Ultimately, the optimum size or number of the above characteristics is a topic of a further analysis. It is possible that the semi-leafless trait present in most commercial cultivars is partially successful because it decreases leaf weight (Klimek-Kopra et al., 2015) and wind resistance in addition to increasing tendril number and vigor. An interesting direction of future research would be to determine the specific plant habit that decreases load to the greatest extent.

Height has a second order quadratic effect on stem stress. Therefore, a doubling in height will increase stem stress fourfold, and a quadrupling in height will increase stem stress by 16 fold. Stem material increases in a linear manner with a doubling in plant height also doubling stem material. In theory, a doubling in height would also increase load by two fold since the stem would be 2 times as long, but a taller plant may not have twice as much seed yield, and based on a small dataset, stems comprise only $10-15 \%$ of the weight of the plant, although this percentage would differ for every variety. Based on the stem stress equation, a pea plant $100 \mathrm{~mm}$ tall will be under 100 fold less bending stress than a pea plant $1000 \mathrm{~mm}$ tall, indicating why peas often lodge at greater growth stages. The relationship is non-linear. While height is a negative characteristic for lodging resistance, tall peas tend to be more competitive with weeds than short pea plants (Wall and TownleySmith, 1996), and a certain amount of height is required for mechanical harvesting. Therefore, pea breeders need to balance the need for more lodging resistant varieties with the need for harvestability and weed suppression.

In the angiosperms, hollow stems are probably common because they are more efficient. However, it is worth noting that increasing stem diameter also comes at a cost to the plant since the amount of plant material increases by a factor of $y$ with every increase in radius (assuming wall thickness is held constant), where $y=\pi r_{2}{ }^{2} / \pi r_{1}{ }^{2}$ and where $r_{1}$ and $r_{2}$ are the initial radius and the increased radius, respectively. If wall thickness and plant height are held constant at $0.44 \mathrm{~mm}$ and $51.2 \mathrm{~cm}$, respectively, which were the mean for those traits in the Delta x RER population and only stem diameter is varied, increasing the stem radius five-fold from 0.5 to $2.5 \mathrm{~mm}$ would decrease the relative amount of stress on the stem by 67.39 fold when wall thickness is held constant at $0.44 \mathrm{~mm}$. The stem area would also increase by 8.14 fold. If stem wall thickness is set to be a proportion of the radial diameter, then stem stress will decrease by a factor of 8 with every doubling in stem diameter. Under these conditions stem area would also increase fourfold with every doubling in stem diameter.

The effect of stem wall thickness was analyzed by holding the load, radius, and length of the tube constant. Holding these parameters constant and varying stem wall thickness will allow the effect of wall thickness on stem stress to be determined.

Given the same stem diameter, plants with a larger stem wall thickness will have less bending stress than genotypes with a thinner wall. However, the maximum bending stress is focused on the outer portion of the stem where it is either being compressed or stretched, and adding material to the middle portion of a beam has only a slight effect (Fig. 4) since it is closer to the neutral axis. Hollow tubes are preferred in many structural engineering applications such as flagpoles and wind turbine towers because they withstand more stress than an equivalent amount of material in a solid rod. Breeding for a more solid stemmed pea line would decrease stem stress, but only slightly. In Fig. 4, the stress on a hollow stem follows an exponential decay curve with each incremental increase in wall thickness reducing stress on the stem less than the previous increase in wall thickness. The relationship is not linear.

Engineers design cantilever beams to support both the weight of the beam and the weight of the load. In peas, stems are rarely vertical. Therefore, increases in stem area increase the load on a stem due to the mechanical advantage associated with an increase in the weight of the plant. An estimate based on a small empirical dataset indicates that stem material makes up $10-15 \%$ of total biomass, but this estimate will differ for every variety. If it could be assumed that stem material influences load by $10 \%$, then the optimum stem wall thickness would be about $30 \%$ of the radial diameter. However, as mentioned previously, stem load is dependent on multiple factors, which have yet to be determined. Figure 4 shows that stress is reduced 5.39 fold by making the stem solid. However, increasing the wall thickness of a stem increases the area of stem material by a factor of $\mathrm{x}$ where $x=\left(\pi r^{2}-\pi(r-T 2)\right) /\left(\pi r^{2}-\pi(r-T 1)\right)$, $r=$ radius, and $T 1$ and $T 2=$ thickness 1 and 2 respectively. In this case, stem area increases 10.3 fold, which would be a significant sink for plant resources and cause an increase stem loading. Wall thickness has a much lower effect per unit of plant material than stem radius.

Although no empirical data on lodging was collected, Beeck et al. (2006) concluded that compressed stem thickness was correlated with lodging resistance. However, the 


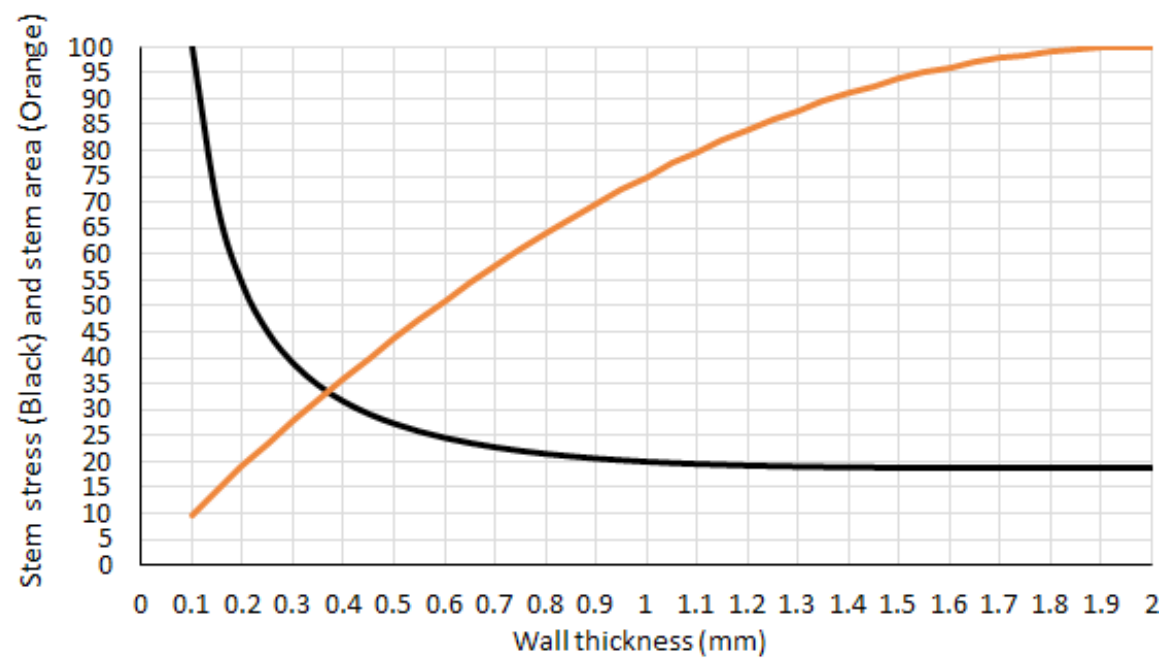

Fig. 4. Load, height, and stem radius were held constant at $0.001 \mathrm{~N} \mathrm{~mm}^{-2}, 514 \mathrm{~mm}$, and $2 \mathrm{~mm}$, respectively. Stem wall thickness was varied from $0.1 \mathrm{~mm}$ (thin walled) to $2 \mathrm{~mm}$ (solid stemmed) in order to determine the effect of wall thickness on stem stress. The Y axis represents the percent stress (black) or percent stem area (orange) of a thin walled $(0.1 \mathrm{~mm})$ and solid stemmed pea stem, respectively. Based on this analysis, stem stress is reduced with increases in stem wall thickness but at an asymptotic rate. The increase in stem area associated with a solid-stemmed line likely would create a significant sink for the plant and also increase stem loading slightly.

three point bending test that was used to measure failure of simply supported (not cantilever) stems is sensitive to specimen geometry. ASTM 790 section 1.2 specifies that cross sections of materials tested with a three point bending test should be both solid and uniformly rectangular (ASTM International, 2019), which is unlike hollow stemmed pea. In a three point bending test a hollow tube is at risk of buckling merely because such a small surface area (the very top of the tube) is supporting the load. It is likely that the strong negative correlation between failure and compressed stem thickness found by Beeck et al. (2006) was merely due to the method of testing. Guo et al. (2013) used a four point bending test and special stiffening plates to prevent buckling in cylindrical beams at the point where pressure was applied, and it is likely that similar techniques would be required for accurate measurements in pea. Based on several site years of data, there was no significant correlation between compressed stem thickness and lodging in the Delta x RER population. Empirical data from this study indicates the wall thickness of a pea stem is approximately $1 / 3$ of the radial diameter, and the stress equation indicates the gains in stress resistance are nearly asymptotic at that point. Therefore, breeding efforts should be focused on increasing stem diameter in pea and reducing load on the stem. It currently is not feasible to reduce plant height significantly because mechanical harvest is required.

The stress equation is a robust engineering model that can predict lodging when estimates of stem diameter, stem wall thickness, and plant height are known, but more importantly, it provides a theoretical basis for lodging resistance in peas. The equation is not completely satisfactory as a model for pea because it does not include such factors as the presence of tendrils, branches, or modifica- tions in the intrinsic strength of the material (more fiber cells or lignin). However, it is a useful starting point for the analysis of the main structural features impacting lodging resistance in pea. It is probable that this simple model could be employed to predict lodging in other crops.

\section{CONCLUSIONS}

1. Plant height and stem diameter are the major factors influencing stress in pea stems. Compressed stem diameter and loading may play a minor role.

2. Stem wall thickness has less of an effect on lodging than was previously believed.

3. The stress equation for a cantilever beam is a robust engineering model that can predict $58 \%$ of lodging when estimates of stem diameter, stem wall thickness, and plant height are known, but more importantly, it provides a theoretical basis for lodging resistance in peas.

4. The equation is not completely satisfactory as a model for pea because it does not take into account the unique truss structure of interlocking sets of tendrils and other factors.

5. It is probable that this simple model could be employed to predict lodging in other crops.

\section{FUNDING SOURCES}

I would like to thank the Montana State University graduate school for funding a Ph.D. Completion Award on my behalf, and the Northern Pulse Growers Association, AGT Foods USA, and the USDA Hatch Act for the majority of the funding for this project. Additional support for my post-doctoral work was received from Rebecca McGee and Clarice Coyne at the USDA-ARS in Pullman, WA. 
Conflict of interest. The authors declare that the research was conducted in the absence of any commercial or financial relationships that could be construed as a potential conflict of interest.

\section{REFERENCES}

ASTM International, 2019. American Society for Testing and Materials (ASTM) ASTM D790. Section 1.2. Accessed: 12/14/2019. https://www.astm.org/Standards/D790.htm https://doi.org/10.1016/0029-1021(68)90030-3

Banniza S., Hashemi P., Warkentin T.D., Vandenberg A., and Davis A.R., 2005. The relationships among lodging, stem anatomy, degree of lignification, and resistance to mycosphaerella blight in field pea (Pisum sativum). Can. J. Botany, 83: 954-967. https://doi.org/10.1139/b05-044

Beeck C.P., Wroth J., and Cowling W.A., 2006. Genetic variation in stem strength in field pea (Pisum sativum L.) and its association with compressed stem thickness. Aust. J. Agric. Res., 57, 193-199. https://doi.org/10.1071/ar05210

Beeck C.P., Wroth J., and Cowling W.A., 2008a. Additive genetic variance for stem strength in field pea (Pisum sativum). Aust. J. Agric. Res., 59, 80-85. https://doi.org/10.1071/ar07069

Beeck C.P., Wroth J.M., Falk D.E., Khan T., and Cowling W.A., 2008b. Two cycles of recurrent selection lead to simultaneous improvement in black spot resistance and stem strength in field pea. Crop Sci., 48, 2235-2244. https://doi.org/10.2135/cropsci2007.11.0647

Blake V., Birkett C.L., Matthews D.E., Hane D., Bradbury P., and Jannink J., 2015. The triticeae toolbox: combining phenotype and genotype data to advance small-grains breeding. The Plant Genome.

https://doi.org/10.3835/plantgenome2014.12.0099

Chen H.F., Shan Z.H., Sha A.H., Wu B.D., Yang Z.L., Chen S.L., et al., 2011. Quantitative trait loci analysis of stem strength and related traits in soybean. Euphytica, 179: 485497. https://doi.org/10.1007/s10681-011-0382-5

Chen H.F., Yang Z.L., Chen L.M., Zhang C.J., Yuan S.L., Zhang X.J., et al., 2017. Combining QTL and candidate gene analysis with phenotypic model to unravel the relationship between lodging and related traits in soybean. Mol. Breeding, 37: 14. https://doi.org/10.1007/s11032-017-0645-5

Elkoca E. and Kantar F., 2006. Response of pea (Pisum sativum L.) to mepiquat chloride under varying application doses and stages. J. Agron. Crop Sci., 192: 102-110. https://doi.org/10.1111/j.1439-037x.2006.00201.x

Fulbright J., Wanner K., Bekkerman A., and Weaver D., 2017. Wheat Stem Sawfly Biology. MT201107AG. Montana State University Extension. http://store.msuextension.org/ publications/agandnaturalresources/mt201107ag.pdf. Accessed: 8/2/2018.

Godoy J., Gizaw S., Chao S., Blake N., Carter A., Cuthbert R., Dubcovsky J., Hucl P., Kephart K., Pozniak C., Prasad P.V., Pumphrey M., and Talbert L., 2018. Genome-wide association study of agronomic traits in a spring-planted North American elite hard red spring wheat panel. Crop Sci., 58: 1838-1852.

https://doi.org/10.2135/cropsci2017.07.0423

Goldenberg J.B., 1965. Afila a new mutation in pea (Pisum sativum L.). Boletin Genetico, 1: 27-31.
Guo L., Yang S., and Jiao H., 2013. Behavior of thin-walled circular hollow section tubes subjected to bending. Thin-Walled Structures, 73: 281-289. https://doi.org/10.1016/j.tws.2013.08.014

Hedden P., 2003. The genes of the green revolution. Trends in Genetics, 19: 5-9. doi:10.1016/s0168-9525(02)00009-4.

Inoue M., Gao Z.S., and Cai H.W., 2004. QTL analysis of lodging resistance and related traits in Italian ryegrass (Lolium multiflorum Lam.). Theor. Appl. Genet., 109: 1576-1585. https://doi.org/10.1007/s00122-004-1791-9

Jha A.B., Arganosa G., Tar'an B., Diederichsen A., and Warkentin T.D., 2013. Characterization of 169 diverse pea germplasm accessions for agronomic performance, Mycosphaerella blight resistance and nutritional profile. Genet. Resour. Crop Ev., 60: 747-761. https://doi. org/10.1007/s10722-012-9871-1

Jha A.B., Tar'an B., Stonehouse R., and Warkentin T.D., 2016. Identification of QTLs associated with improved resistance to ascochyta blight in an interspecific pea recombinant inbred line population. Crop Sci., 56: 2926-2939. https://doi.org/10.2135/cropsci2016.01.0001

Kaatz D. and Gritton E.T., 1975. Yield and height response to anti lodging treatments in peas. Scientia Horticulturae (Amsterdam), 3: 359-365. https://doi.org/10.1016/0304-4238(75)90050-3

Klimek-Kopyra A., Gląb T., and Lorenc-Kozik A., 2015. Estimation of tendrils parameters depending on the sowing methods, in contrasting Pisum sativum L. varieties. Rom. Agric. Res., 32: 239-244.

Kof E.M., Oorzhak A.S., Vinogradova I.A., Kalibernaya Z.V., Krendeleva T.E., Kukarskikh G.P., et al., 2004. Leaf morphology, pigment complex, and productivity in wildtype and afila pea genotypes. Russ. J. Plant Physiol., 51: 449-454.https://doi.org/10.1023/b:rupp.0000035735.76190.6c

Kosev V. and Mikic A., 2012. Short communication. Assessing relationships between seed yield components in springsown field pea (Pisum sativum L.) cultivars in Bulgaria by correlation and path analysis. Span. J. Agric. Res., 10: 1075-1080. https://doi.org/10.5424/sjar/2012104-3025

McPhee K.E. and Muehlbauer F.J., 1999. Stem strength in the core collection of Pisum germplasm. Pisum Genetics, 31: 21-23.

Mendel, Gregor. 1866. Versuche über Plflanzenhybriden. Verhandlungen des naturforschenden Vereines in Brünn, Bd. IV für das Jahr 1865, Abhandlungen, 3-47.

Mikel M.A., 2013. Ancestry and characterization of US contemporary proprietary garden pea (Pisum sativum L. convar. medullare Alef.) germplasm. Genet. Resour. Crop Ev., 60: 2207-2217. https://doi.org/10.1007/s10722-013-9986-Z

Murfet I.C. and Reid J.B., 1993. Developmental mutants in peas: Genetics, molecular biology and biotechnology by R. Casey and D.R. Davies, 165-216.

Niklas K., Spatz H.-C., and Vincent J., 2006. Plant biomechanics: An overview and prospectus. Am. J. Bot., 93: 1369-1378. https://doi.org/10.3732/ajb.93.10.1369

Rasdorsky W., 1929. Über die Baumechanik der Pflanzen (Teil I-III). Biologia generalis. Internationales Archiv für allgemeine Fragen der Lebensforschung, 5: 63-94.

Schouls J. and Langelaan J.G., 1994. Lodging and yield of dry 
peas (Pisum sativum L.) as influenced by various mixing ratios of a conventional and a semi-leafless cultivar. J. Agronomy and Crop Sci., 172: 207-214. https://doi.org/10.1111/j.1439-037x.1994.tb00168.x

Schwendener S., 1874. Das mechanische Prinzip im anatomischen Bau der Monocotylen mit vergleichenden Ausblicken auf die u"brigen Pflanzenklassen. Engelmann, Leipzig, Germany. https://doi.org/10.5962/bhl.title.105632

Shah A.N., Tanveer M., Rehman A.U., Anjum S.A., Iqbal J., and Ahmad R., 2017. Lodging stress in cereal-effects and management: an overview. Environ. Sci. Poll. Res., 24: 5222-5237. https://doi.org/10.1007/s11356-016-8237-1

Schulgasser K. and Witztum A., 1992. On the strength, stiffness and stability of tubular plant stems and leaves. J. Theor. Biol., 155: 497-515. https://doi.org/10.1016/s0022-5193(05)80632-0

Singh A.K. and Srivastava C.P., 2015. Effect of plant types on grain yield and lodging resistance in pea (Pisum sativum L.). Indian J. Gen. Pl. Br., 75: 69-74. https://doi.org/10.5958/0975-6906.2015.00008.5

Skubisz G., Kravtsova T.L., and VelikanovL.P., 2007. Analysis of the strength properties of pea s tems. Int. Agrophysics, 21, 189-197.

Smitchger J. and Weeden N., 2019. Quantitative trait loci controlling lodging resistance and other important agronomic traits in dry field peas. Crop Sci., 59, 1442-1456. https://doi.org/10.2135/cropsci2018.04.0260

Spies J.M., Warkentin T., and Shirtliffe S.J., 2010. Basal branching in field pea cultivars and yield-density relationships. Can. J. Plant Sci., 90: 679-690.

https://doi.org/10.4141/cjps09195
Stelling D., 1989. Problems of breeding for improved standing ability in dried peas, Pisum sativum L. J. Agron. Crop Sci., 163: 21-32.

https://doi.org/10.1111/j.1439-037x.1989.tb00733.x

Stubbs C.J., Baban N.S., Robertson D.J., Alzube L., and Cook D.D., 2018. Bending stress in plant stems: Models and Assumptions. In: Plant Biomechanics (Eds A. Geitmann, J. Gril). Springer, Cham. https://doi.org/10.1007/978-3-319-79099-2_3

Swinhoe R., McCann M., Rameau C., Smith A., and Wang T., 2001. Reinforcing stem architecture in peas. Proc. 4th Eur. Conf. Grain Legumes: Towards a sustainable production of healthy food and novel products, 8-12 July, Cracow, Poland. European Association of Grain Legume Research, Executive Secretariat, Paris, 290-291.

Tar'an B., Warkentin T., Somers D.J., Miranda D., Vandenburg A., Blade S., et al., 2003. Quantitative trait loci for lodging resistance, plant height and partial resistance to mycosphaerella blight in field pea (Pisum sativum L.). Theor. Appl. Genet., 107: 1482-1491. https://doi.org/10.1007/s00122-003-1379-9

Wall D. and Townley-Smith L., 1996. Wild mustard (Sinapis arvensis) response to field pea (Pisum sativum) cultivar and seeding rate. Can J. Plant Sci., 76: 907-914. https://doi.org/10.4141/cjps96-152

Wang T.F., Gossen B.D., and Slinkard A.E., 2006. Lodging increases severity and impact of mycosphaerella blight on field pea. Can. J. Plant Sci., 86: 855-863. https://doi.org/10.4141/p05-094

Xue J., Zhao Y.S., Gou L., Shi Z.G., Yao M.N., and Zhang W.F., 2016. How high plant density of maize affects basal internode development and strength formation. Crop Sci., 56: 3295-3306. https://doi.org/10.2135/cropsci2016.04.0243 